\title{
Utility of the Occupation-Centered Intervention Assessment for Occupational Therapy Level I Fieldwork
}

\author{
Nora Frigo \\ Creighton University, United States of America \\ Emily Hanneman \\ Creighton University, United States of America \\ Adrianne Kashale \\ Creighton University, United States of America \\ Margaret Sutton \\ Creighton University, United States of America \\ Erin Wright \\ Creighton University, United States of America \\ Vanessa D. Jewell* \\ Creighton University, United States of America
}

\begin{abstract}
This study examined the utility of the Occupation-Centered Intervention Assessment (OCIA) among occupational therapy students and their perceptions of the use of an occupation-centered approach to design interventions during level I fieldwork. Twenty-five students completed training on the OCIA, used the tool on level 1 fieldwork, and then completed a post-test survey containing closed and open-ended questions. Content analysis was used to analyze open-ended questions. Descriptive statistics was used to analyze quantitative data. Overall, students $(N=25)$ found the OCIA to be a beneficial tool to utilize during fieldwork experiences to recognize and develop interventions from an occupation-centered approach. Currently the Occupational Therapy Practice Framework and models of practice are the primary tools available for student reflection for intervention design. The findings of this study supported the need for a reflection tool to aide in the development and implementation of occupation-centered reasoning during fieldwork experiences.
\end{abstract}

Keywords: clinical competence; fieldwork; occupational therapy; reflection; teaching

${ }^{*}$ Corresponding Author: Vanessa D. Jewell, PhD, OTR/L, School of Pharmacy and Health Professions, Creighton University, 2500 California Plaza, Omaha, NE 68178 United States of America

Journal URL: https://publications.coventry.ac.uk/index.php/pblh/index

Email: vanessajewell@creighton.edu

Frigo, N., Hanneman, E., Kashale, A., Sutton, M., Wright, E., and Jewell, V.D. (2019) 'Utility of the occupation-centered intervention assessment for occupational therapy Level I fieldwork'. International Journal of Practice-based Learning in Health and Social Care, 7 (1), 64-74 https://doi.org/10.18552/ijpblhsc.v7i1.510

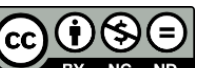

BY NC ND (c) 2019 Nora Frigo, Emily Hanneman, Adrianne Kashale, Margaret Sutton, Erin Wright, and Vanessa D. Jewell. This Open Access article is distributed under the terms of the Creative Commons Attribution Attribution-NonCommercial No Derivatives 4.0 International License (https://creativecommons.org/licenses/by-nc-nd/4.0/ ), which permits unrestricted non-commercial use, distribution, and reproduction in any medium, provided the original work is properly cited and is unaltered. 


\section{Background}

The development of several occupation-focused models of practice in the 1970s and 1980s led to a resurgence on the focus of occupation as the primary means and end of intervention (Wong and Fisher 2015). Occupational therapy education instructors began to teach the importance of occupation and researchers shifted to examine the effectiveness of the use of occupation as a therapeutic modality. The top three occupation-focused models incorporated into academic curriculum include the Canadian Model of Occupational Performance and Engagement (CMOP$\mathrm{E})$, the Model of Human Occupation (MOHO), and the Person-Environment-OccupationPerformance Model (PEOP) (Ashby and Chandler 2010). However, occupational therapy students have difficulty applying these common models of practice while on fieldwork (Ashby and Chandler 2010), as students indicated that the models of practice were not concrete and difficult to apply to clinical practice (Hodgetts et al. 2007). One student reported that the models of practice were too abstract and found them to be impractical while forming intervention sessions (Hodgetts et al. 2007). Moreover, occupational therapists report misunderstandings of these theoretical concepts and how they can help guide intervention (Wong and Fisher 2015). Occupational therapists believe they have a lack of understanding about these theoretical concepts and an inconsistency in the use of these models (Wong and Fisher 2015). Many occupational therapy students and practitioners do not find the models of practice useful while developing interventions from an occupation-centered approach, however, it is stated that these conceptual foundations provide justification for the need of occupational therapy services (Keilhofner 1992). An occupation-centered approach to practice involves provision of clientcentered, occupationally relevant, and ecologically valid interventions (Jewell and Pickens 2017).

In addition to the use of models of practice, the American Occupational Therapy Association (AOTA) developed the Occupational Therapy Practice Framework (Framework) as a resource for practitioners and students to use throughout the development of intervention (American Occupational Therapy Association 2014). The use of the Framework is emphasized throughout educational curricula as it provides students with a guide to understand the basic tenets and vision of the profession, as well as a description of the occupational therapy process (American Occupational Therapy Association 2014). Although the Framework acts as a guide for students throughout their classroom education, students often have difficulty applying various components of the Framework during fieldwork (Gutman et al. 2007). One factor that leads to students' misunderstanding is a lack of clarity for the use of clinical terms in addressing client deficits. Students have the skills to identify specific client dysfunctions with the use of the Framework, but struggle to address these dysfunctions through intervention (Gutman et al. 2007).

\section{Occupation-Centered Intervention Assessment}

The Occupation-Centered Intervention Assessment (OCIA) is a resource for students, practitioners, and educators to use to determine their use of an occupation-centered approach in occupational therapy practice (Jewell and Pickens 2017). Occupation-centered is defined as a lens or perspective used to guide clinical reasoning and the occupational therapy process (Fisher 2013). This approach ensures that the therapy process is rooted in occupation, includes personally meaningful interventions, and carefully examines the client's context and environment. The OCIA consists of three continua that rank the personal, contextual, and occupational relevance of interventions on a five-point ordinal scale (Jewell and Pickens 2017). A higher score on all three continua indicates that greater occupation-centered reasoning was used to design the intervention. Research thus far on the OCIA found the psychometric properties of the tool to have good content validity and utility, and substantial inter-rater reliability ( $r=0.856)$ (Jewell, Burkley, Kaufman 2017, Jewell and Pickens 2017). A separate study analyzed the use of occupation-centered practice among practitioners at a skilled-nursing facility to determine therapist use of occupation-based and occupation-focused interventions in practice (Jewell et al. 2016). Results of this study concluded that over half of therapy time within a skilled-nursing facility was spent completing non-occupational tasks (Jewell et al. 2016). 
A primary intention of the OCIA is for students to self-reflect during fieldwork experiences. Students may use the OCIA as a guide to design interventions that are more ecologically valid, client-centered, and occupation-based and/or focused (Jewell and Pickens 2017). Occupationbased and occupation-focused differ from occupation-centered in that these terms describe how interventions are performed, whereas occupation-centered refers to a reasoning process used in practice (Jewell et al. 2016). An occupation-based intervention is one in which a client is actively completing an occupation as the primary part of the intervention process for occupational therapy (Fisher 2013). For example, utilizing an occupation-based intervention, an occupational therapist working with a client who experienced a traumatic brain injury completes therapy in a kitchen baking a pan of brownies. The patient is working to improve balance, standing, and safely manipulating objects in a natural context. The intervention of baking in the kitchen is occupation-based because the client is actively engaged in an occupation (i.e., baking), however, the primary focus of this intervention is on improvement of client factors (i.e., increasing balance and endurance). The intention of occupation-focused interventions is to concentrate directly on an occupation (Fisher 2013). Using the same example, the patient participates in an education session focusing on improving overall baking performance through collaborative discussion about the client's specific recommendations to improve occupational performance (e.g., adaptations, energy conservation techniques, and safety as it directly relates to baking). An intervention becomes both occupation-based and focused when the client is actively engaged in completing an occupation (e.g., baking) and the focus of the session is to improve the occupation (e.g., baking).

The use of occupation as a means and focus of intervention is a core concept to the field of occupational therapy (Fisher 2013, Gustafsson and McKenna 2010). Occupational therapy is centered on enabling clients to participate and engage in meaningful occupations to increase client performance (Aiken et al. 2011). Despite knowledge of occupation-focused models of practice and valuing occupation, a lack of utilization of occupation as a therapeutic medium remains in both the fieldwork setting and clinical practice. New occupational therapy graduates reported it has taken between six months and two years to become competent in their occupation-centered reasoning skills (Hodgetts et al. 2007). It appears there is a lack of confidence within students on fieldwork in preparing interventions from an occupation-centered approach. Therefore, there is a need for a tool or reflection guide for students to use on level I fieldwork to aid in design and implementation of interventions.

The OCIA was developed to guide students and practitioners in the design and implementation of interventions from an occupation-centered approach, therefore, a study was needed to focus on students' perceptions on the usefulness of the tool. The purpose of this study was to determine the utility of the OCIA and ease of scoring interventions within occupational therapy rehabilitation settings according to level I fieldwork student observations. Thus, the following research questions were explored: What are the students' perceptions on the ease of scoring the OCIA? What are the students' perceptions on the usefulness of the OCIA training prior to their level I fieldwork experience? Did the OCIA help students better understand the use of occupation during observation of an intervention session led by their fieldwork educator?

\section{Method}

\section{Design}

The study employed a post-test only survey design utilizing open-ended and close-ended questions. The survey design intended to be an efficient and effective tool for learning about students' opinions and behaviors regarding the OCIA (Dillman, Smyth, and Christian 2014). The survey was titled the Utility of OCIA Post-Fieldwork Questionnaire. 


\section{Participants}

The inclusion criteria included enrollment as a second-year entry-level doctoral occupational therapy student at Creighton University in the United States of America, attendance at the OCIA training, completion of a level I fieldwork, and scoring at least one therapy session using the OCIA. All students graduated from a baccalaureate program prior to admission to the occupational therapy clinical doctoral program. During the entry-level clinical doctoral program, the occupational therapy students enroll in two years of full-time didactic instruction and then one year of full-time experiential education. The level I fieldwork experience occurs during the didactic portion of the curriculum, and included 40 hours of clinical observation and participation in the occupational therapy process. Each level I fieldwork experience required the student to develop a minimum of one intervention session and then review and reflect with the fieldwork educator. All students completed a physical rehabilitation level I fieldwork experience. Scoring of at least one therapy session is defined as scoring all three continua of the OCIA for one intervention utilized during a therapy session. Exclusion criteria included students under the age of 19 and failure of level I fieldwork course. This study received Institutional Review Board approval, and all students provided informed consent.

\section{Measure}

The research team developed the Utility of OCIA Post-Fieldwork Questionnaire (Figure 1) to measure students' perceptions on the utility of the OCIA. In addition, the research team used Smart's model of clinical utility as a guide to develop questions related to clinical utility (Smart 2006). This model of clinical utility provides a list of important components of a clinical utility study including ease of use, training, meaning and relevance, timing, format, and interpretation. In order to improve content validity, an expert panel of four occupational therapists and one bioethicist skilled in survey and research design, reviewed and provided feedback on the survey.

The 22-question survey included seven demographic questions, nine close-ended questions, and six open-ended questions. The use of nine close-ended questions, allowed quantitative data analysis to be obtained using both three-point (two questions) and five-point Likert Scale questions (seven questions). The survey also included six open-ended questions to capture students' perceptions of the OCIA and increase the understanding of the clinical utility of the OCIA.

Figure 1. Excerpt from Utility of OCIA Post-Fieldwork Questionnaire

\begin{tabular}{|c|c|c|c|c|}
\hline \multicolumn{5}{|c|}{ Was the format of the Occupation-Centered Intervention Assessment easy to follow? } \\
\hline $\begin{array}{l}1 \\
\text { Very Hard }\end{array}$ & $\begin{array}{l}2 \\
\text { Somewhat Hard }\end{array}$ & $\begin{array}{l}3 \\
\text { Neutral }\end{array}$ & $\begin{array}{l}4 \\
\text { Somewhat Easy }\end{array}$ & $\begin{array}{l}5 \\
\text { Very Easy }\end{array}$ \\
\hline \multicolumn{5}{|c|}{$\begin{array}{l}\text { Do you think the Occupation-Centered Intervention Assessment training adequately prepared you } \\
\text { to score a treatment session using the Occupation-Centered Intervention Assessment? }\end{array}$} \\
\hline $\begin{array}{l}1 \\
\text { Not Prepared } \underline{\underline{A t}} \\
\text { All }\end{array}$ & $\begin{array}{l}2 \\
\text { Not Very } \\
\text { Prepared }\end{array}$ & $\begin{array}{l}3 \\
\text { Neutral }\end{array}$ & $\begin{array}{l}4 \\
\text { Somewhat } \\
\text { Prepared }\end{array}$ & $\begin{array}{l}5 \\
\text { Very Prepared }\end{array}$ \\
\hline
\end{tabular}

\section{Procedure}

The researchers emailed all $(n=79)$ second-year entry-level occupational therapy doctoral students to invite them to participate in the study. Researchers utilized convenience sampling to ensure the largest possible sample size. One week prior to the OCIA training session, a second email was sent as a reminder for individuals interested in participating in the study. The students completed a one-hour training session on the OCIA in a classroom setting. Forty students attended the OCIA training. The training included a brief overview of the tool, scoring instructions, and four videos of occupational therapy interventions to allow for practice scoring 
interventions with the OCIA. The research team was available to answer questions throughout the training session.

Students received an OCIA score sheet via email three weeks prior to level I fieldwork to allow for scoring of therapy sessions during fieldwork experience. An email was sent at the beginning of the level I fieldwork experience to remind students to complete the scoring of at least one therapy session throughout the week. A second, and final, reminder email was sent out at the end of the fieldwork.

After completion of level I fieldwork, the Utility of OCIA Post-Fieldwork Survey was sent via email to students who participated in the training. Students then had three weeks to complete the anonymous survey. A weekly reminder email was sent out for three weeks until closure of the survey. The researchers administered the survey through a secure anonymous survey system to distribute, gather, store, and analyze data.

\section{Data analysis}

The researchers analyzed the close-ended questions using descriptive statistics. Statistical Package for the Social Sciences (SPSS, Version 24; IBM Corp., Armonk, NY) was used to analyze mean and frequency percentages of the data. The researchers utilized a general inductive approach to analyze open-ended questions (Thomas 2006). Responses from openended questions were compiled into a single Microsoft ${ }^{\circledR}$ Word document for ease of review. The researchers then individually read and re-read the responses in order to gain an overall insight into the data. The research team then identified common terms and phrases that appeared frequently in the data. These common terms and phrases were compiled into a chart, and frequency counts were calculated. Related terms and phrases were grouped together into categories, and similar categories were combined into two overarching elements related to answering the research questions.

To establish trustworthiness, the researchers provided a thick description of the research process (Curtin and Fossey 2007). Researcher triangulation was used to reduce single researcher bias within the data analysis process by having multiple research members independently and collaboratively code the open-ended questions (Curtin and Fossey 2007). The use of open- and close-ended questions increased trustworthiness by using methodological triangulation (Curtin and Fossey 2007). Collaboration occurred through verbal discussion among the researchers to reflect upon the results (Curtin and Fossey 2007).

\section{Results}

The population sample of this study was 79 second-year graduate occupational therapy students. Forty students consented and participated in the training session, and 27 elected to complete the survey. However, two students were not second-year students and were excluded from the data analysis leaving a total of 25 students. Of the 25 completed surveys, participants ranged in age from 22-33, with an average age of 23.36 years old. Level I fieldwork placement settings varied, however, the three most common settings included inpatient acute rehabilitation $(n=6 ; 24 \%)$ outpatient hand clinic $(n=4 ; 16 \%)$, and skilled nursing facility $(n=3 ; 12 \%)$.

\section{Close-ended questions}

\section{Training, ease of use, and scoring}

The quantitative data analysis revealed that the majority of students $(n=23 ; 92 \%)$ found the training prior to fieldwork helpful to understand how to administer the OCIA while on level I fieldwork. The findings showed all students found the instructions of the OCIA clear, concise, and easy to follow (Figure 2). Ninety-six percent of students $(n=24)$ said that they would utilize the OCIA during level II fieldwork experience to develop an intervention from an occupationcentered approach (Figure 3). Ninety-six percent of students $(n=24)$ reported that the training 
was either extremely $(36 \%)$ or somewhat adequate $(60 \%)$ in preparing them for use of the tool on fieldwork (Figure 4).

Figure 2. Students' perception on ease of scoring the OCIA

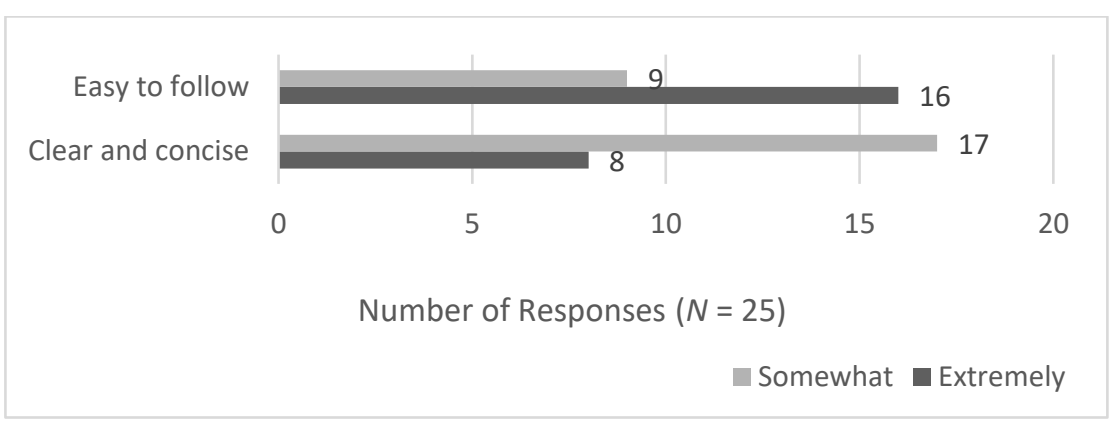

Figure 3. Percentage of students' projected use of the OCIA during level II fieldwork

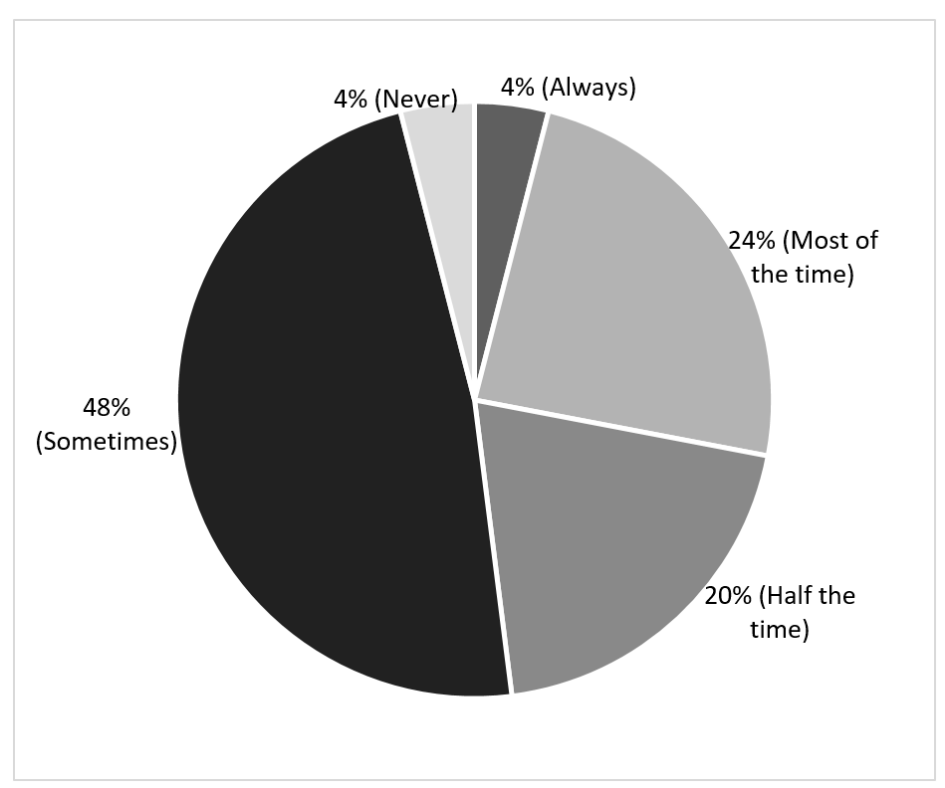

Figure 4. Students' perception of the adequacy of the OCIA training

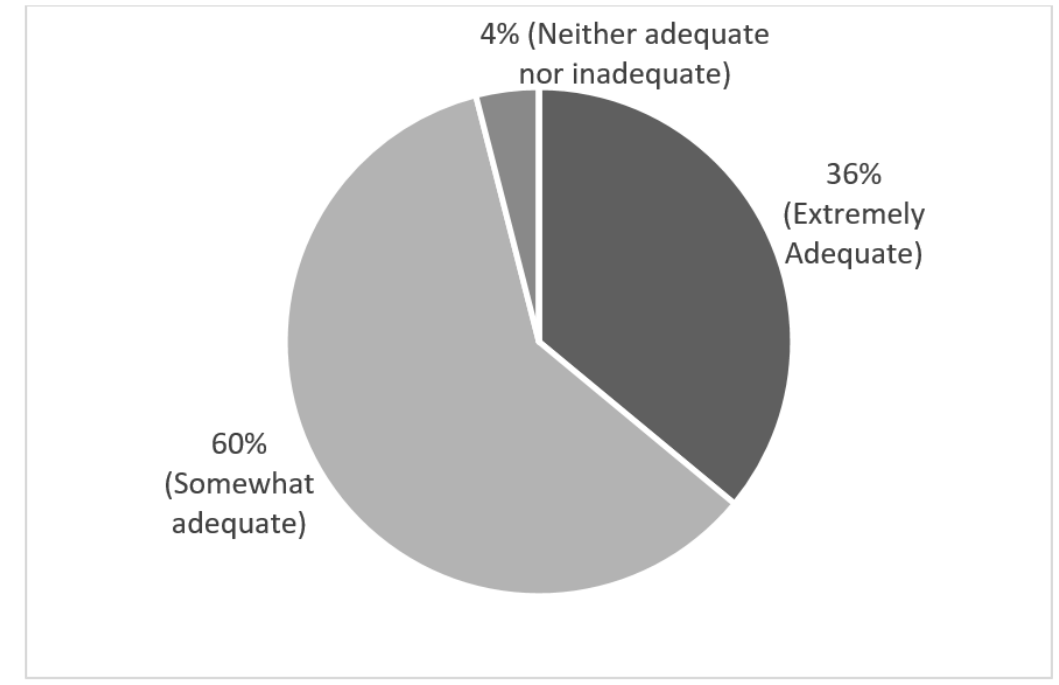




\section{Open-ended questions}

The analysis of open-ended questions provided an in-depth description of students' perceptions of the OCIA and their understanding and value of occupation. The two key elements that emerged were: utilization of an occupation-centered approach during fieldwork and factors influencing future use of the OCIA and occupation-centered reasoning. Element two revealed two sub-elements: the influence of practice setting, and student's level of experience.

\section{Utilization of an occupation-centered approach during fieldwork}

Many of the students reported that the tool was beneficial in helping them establish an occupation-centered approach for interventions or to utilize as occupation as the therapeutic modality. 'It was beneficial because it helped me realize or look into my intervention strategies and see if they relate to my patient's desired occupations.' Students reported that the tool allowed for mindfulness and reflection on implemented interventions. 'The tool increased mindfulness of client-centered practice.'

\section{Factors influencing future use of the OCIA and occupation-centered reasoning}

Many of the students discussed factors that would influence their use of the OCIA along with the likelihood of developing interventions from an occupation-centered approach during both future fieldwork experience and clinical practice after graduation. The factors influencing future use of the OCIA has been split into two sub-elements to adequately convey student perceptions of future use of the OCIA.

\section{Influence of the practice setting}

At the time of the survey, the students had recently completed their level IC fieldworks in various practice settings. Students reported easily using occupation-centered reasoning in the following practice settings: inpatient rehabilitation, pediatrics (e.g. outpatient, school-based), and skilled nursing facilities. One participant stated, 'Yes, in the school setting we worked on skills that were directly necessary for their success in the classroom.' Students in these settings found they had more time to reflect using the OCIA to help create interventions that were meaningful to the client. Additionally, students could easily see a connection to creation of client-centered and occupation-based interventions in these settings.

Students reported difficulty using occupation-centered reasoning in settings such as hand therapy and acute care. 'Acute care is so fast paced that it can be hard to make things clientcentered' and another student explained, 'In acute care sometimes patients are limited to what they can do because of their pain or other medical circumstances. Because of that, having occupation-centered interventions can be difficult.' Students in these settings found they had less time to reflect because of productivity standards, busy caseloads, and limited time with clients. '.. in acute care time was tight, but I think this would have helped them to better identify what was important to the patient.' 'But realistically, I do not know what the productivity level will be at my site where I am working.' One participant reported that 'I would rarely use it in an outpatient hand setting because interventions tend to be less occupation-based in that setting.' Students explained that the practice area was a determining factor on whether they found the tool useful and relevant for taking time to complete or reflect upon their interventions.

\section{Student level of experience determines use of OCIA}

Many of the students stated they would use this tool during either level II fieldwork experiences or as an entry-level therapist. One participant predicted that she would use the OCIA when first entering clinical practice, 'When I start working as an OT [occupational therapist], the OCIA will assist me in creating the best interventions for my clients'. Another participant stated, 'I think using this tool once every couple of weeks can help us as students focus on occupation-based practice and not lose sight of our field's mission and practice'. However, as students gain 
experience in the field as a therapist they would use the tool less frequently due to better clinical reasoning. One participant stated '... once I become more experienced I am not sure if I would continue to use it or not'. Overall, the students felt that with more clinical experience they would be able to utilize an occupation-centered approach to interventions, thus, the tool would no longer be needed.

\section{Discussion}

Limited resources are available within the field of occupational therapy to guide students and new practitioners in the development of occupation-centered interventions. Throughout occupational therapy curriculum there is a strong emphasis on the utilization of the Framework along with models of practice to develop interventions; however, these do not allow for a quick and efficient reflection of designing interventions that use an occupation-centered approach. Therefore, the purpose of this study was to determine the utility of the OCIA and how it can be utilized as a reflective tool for students during fieldwork experiences.

Results of this study indicated an overall student perception that the OCIA was easy to score and able to capture occupation-centered interventions. Students expressed they would utilize the OCIA during future level II fieldwork to score and design interventions that are occupationcentered. This was an expected result as previous research on the OCIA indicated that the use of numbers along the continua provided a clear and easy way for occupational therapists and students to score the OCIA (Jewell and Pickens 2017).

Students reported that the training on the OCIA was beneficial and aided in the understanding of the use of the tool. This was an anticipated result as the OCIA training was updated based upon past research to help students better understand how to score an intervention session. Overall, students found the OCIA training to be useful, which allowed for ease of scoring while on their fieldwork experiences. This finding was associated with the changes made to the individual continua levels in previous research to improve clarity and ease of scoring (Jewell and Pickens 2017).

Although many students found the tool to be beneficial on their level I fieldwork experiences, some reported that using an occupation-centered approach to design interventions may not always be applicable in certain practice settings or with certain patient populations. Despite $96 \%$ of students reporting that they would use the tool while on level II fieldwork, it was apparent that students would only use the tool if it aligned with the values of the practice setting. Practice settings, such as hand therapy or acute care, pose additional barriers to occupation-centered practice as they are more likely to follow a medical model. These barriers to practice caused students to follow current practice trends (e.g. use of the biomechanical model) instead of using theoretical models of practice (e.g. MOHO, CMOP-E, PEOP) to guide their reasoning.

Students who completed fieldwork experiences in an outpatient hands clinic found it hard to apply the OCIA. Students stated that their clinical instructors used more of a biomechanical approach in designing interventions. These findings align with current research as hand therapists primarily focus on body structures and functions (Fitzpatrick and Presnell 2004, Rose et al. 2011). Various studies recognize both the challenges and benefits of using an occupationcentered approach to services in the hand therapy setting (Bachman 2016, Colainni et al. 2015). Some benefits of using occupations in the hand therapy setting include facilitating meaningful experiences, functional activity, and holism for clients (Colaianni and Provident 2010). To utilize an occupation-centered approach within the hand therapy setting, students and practitioners must continue to familiarize themselves with occupational therapy models of practice and philosophies, and in turn apply both in practice (Colaianni et al. 2015).

Students indicated their level of clinical experience would influence their use of the OCIA during practice. Students reported that the OCIA would be utilized more as students and entry-level practitioners to aid in the development of interventions that are client- and occupation-centered. 
This was a moderately expected result as students and entry-level practitioners gain clinical experience they would decrease their use of the OCIA to aid in designing interventions. Although, current research suggests it is important for all levels of experienced practitioners to utilize a reflection tool to prevent inflexible and biased practice (Anders Ericsson 2009).

Students stated they would use the OCIA as a reflection tool both during and after implementing an intervention to analyze their intervention design. This was an expected result, because the use of reflection allows practitioners to review the impact of interventions and interactions and use their analysis to change their future practice and outcomes (Epstein, Siegel, and Silberman 2008, McConnell et al. 2012). According to Weinstein (2013), when occupational therapists use self-reflection it promotes competency and problem solving to improve patient outcomes. This research suggests that the OCIA could be used as a reflection tool for students while on fieldwork experiences.

\section{Limitations}

A limitation of this study is that it focused on second-year occupational therapy students from a single university completing their level I fieldwork experience, as students completing their level II fieldwork had already been invited to participate in a previous OCIA research study. Therefore, a small sample size was utilized and the results of this study may not be generalizable across all occupational therapy students. Additionally, this study only reflects the perceptions of a level I fieldwork student with novice clinical reasoning skills, and it does not include the perceptions of practicing occupational therapists. For that reason, the results of this study cannot be generalized to occupational therapy practitioners who exhibit proficient clinical reasoning skills. There is a potential for response bias as the survey was not standardized, and students could have misinterpreted the meaning of the questions (Forsyth and Kviz 2006). Additionally, there is the potential for recall bias as the survey remained open for two weeks after fieldwork experiences (Forsyth and Kviz 2006). Lastly, response choices may not have accurately expressed the students' opinions. One attempt to overcome this limitation was to include open-ended questions in the survey so students could expand upon their fieldwork experiences.

\section{Conclusion}

The aim of this study was to determine students' perceptions of the utility and ease of scoring occupational therapy interventions using the OCIA while on level I fieldwork. The results of this study found that the majority of students projected they would utilize the OCIA during their level II fieldwork experience and in future practice. Additionally, descriptive results indicated that the OCIA was helpful in developing interventions utilizing an occupation-centered approach; however, factors that contributed to students' perceived use of the OCIA were the practice setting and level of experience. As the field of occupation therapy is constantly changing and expanding, it is vital to have a reflection tool integrated into the curriculum to build a foundation for occupation-centered interventions.

\section{Acknowledgements}

The authors would like to thank all of the participants who graciously gave their time to participate in this study. We also would like to Dr. Brenda Coppard who provided insightful critique of this manuscript. 


\section{References}

Aiken, F.E., Fourt, A.M., Cheng, I.K.S., and Polatajko, H.J. (2011) 'The meaning gap in occupational therapy: Finding meaning in our own occupation'. Canadian Journal of Occupational Therapy, 78 (5), 294-302 https://doi.org/10.2182/cjot.2011.78.5.4

American Occupational Therapy Association. (2014) 'Occupational therapy practice framework': Domain and process'. 3rd edn. American Journal of Occupational Therapy, 68 (Suppl. 1), S1-S48. Available from http://dx.doi.org/10.5014/ajot.2014.682006 [1 August 2017]

Anders Ericsson, K. (ed.) (2009) Development of professional expertise: Toward measurement of expert performance and design of optimal learning environments. Cambridge: Cambridge University Press https://doi.org/10.1017/CBO9780511609817

Ashby, S. and Chandler, B. (2010) 'An exploratory study of the occupation-focused models included in occupational therapy professional education programmes'. British Journal of Occupational Therapy, 73 (12), 616-624 https://doi.org/10.4276/030802210X12918167234325

Bachman, S. (2016) 'Evidence-based approach to treating lateral epicondylitis using the occupational adaptation model'. American Journal of Occupational Therapy, 70 (2), 7002360010. Available from https://doi.org/10.5014/ajot.2016.016972

Colaianni, D., and Provident, I. (2010) 'The benefits of and challenges to the use of occupation in hand therapy'. Occupational Therapy in Health Care, 24 (2), 130-146 https://doi.org/10.3109/07380570903349378

Colaianni, D., Provident, I., DiBartola, L.M., and Wheeler, S. (2015) 'A phenomenology of occupation-based hand therapy'. Australian Occupational Therapy Journal, 62 (3), 177186 https://doi.org/10.1111/1440-1630.12192

Curtin, M., and Fossey, E. (2007) 'Appraising the trustworthiness of qualitative studies: Guidelines for occupational therapists'. Australian Occupational Therapy Journal, 54 (2), 88-94 https://doi.org/10.1111/i.1440-1630.2007.00661.x

Dillman, D.A., Smyth, J.D., and Christian, L.M. (2014) Internet, mail and mixed-mode surveys: The tailored design method. 4th edn. Hoboken, NJ: John Wiley and Sons

Epstein, R., Siegel, D., and Silberman, J. (2008) 'Self-monitoring in clinical practice': A challenge for medical educators'. Journal of Continuing Education in the Health Professions, 28 (1), 5-13 https://doi.org/10.1002/chp.149

Fisher, A.G. (2013) 'Occupation-centered, occupation-based, occupation-focused: Same, same or different?' Scandinavian Journal of Occupational Therapy, 20 (3), 162-173 https://doi.org/10.3109/11038128.2012.754492

Fitzpatrick, N. and Presnell, S. (2004) 'Can occupational therapists be hand therapists?' The British Journal of Occupational Therapy, 67 (11), 508-510 https://doi.org/10.1177/030802260406701107

Forsyth, K. and Kviz, F.J. (2006) 'Survey research design'. in Research in Occupational Therapy: Methods of Inquiry for Enhancing Practice. ed. by Kielhofner, G. Philadelphia, PA: F. A. Davis, 91-109 
Gustafsson, L. and McKenna, K. (2010) 'Is there a role for meaningful activity in stroke rehabilitation?' Topics in Stroke Rehabilitation, 17 (2), 108-118 https://doi.org/10.1310/tsr1702-108

Gutman, S.A., Mortera, M.H., Hinojosa, J., and Kramer, P. (2007) 'Revision of the occupational therapy practice framework'. American Journal of Occupational Therapy, 61 (1), 119126 https://doi.org/10.5014/ajot.61.1.119

Hodgetts, S., Hollis, V., Triska, O., Dennis, S., Madill, H., and Taylor, E. (2007) 'Occupational therapy students' and graduates' satisfaction with professional education and preparedness for practice'. Canadian Journal of Occupational Therapy, 74 (3), 148-160 https://doi.org/10.1177/000841740707400303

Jewell, V., Pickens, N.D., Hersch, G., and Jensen, G. (2016) 'An exploration into occupationcentered practice in skilled nursing facilities.' Physical \& Occupational Therapy in Geriatrics, 34 (1), 43-56 https://doi.org//10.3109/02703181.2015.1114062

Jewell, V., Burkley, J., and Kaufman, T. (2017) Inter-rater Reliability of the Occupation-Centered Intervention Assessment in Adult Physical Rehabilitation. Unpublished manuscript. Omaha, NE: Creighton University

Jewell, V. and Pickens, N. (2017) 'Psychometric evaluation of the Occupation-Centered Intervention Assessment'. OTJR: Occupation, Participation, and Health, 37 (2), 82-88 https://doi.org/10.1177/1539449216688619

Kielhofner, G. (1992) Conceptual Foundations of Occupational Therapy. Philadelphia, PA: F.A. Davis

McConnell, M.M., Regehr, G., Wood, T.J., and Eva, K.W. (2012) 'Self-monitoring and its relationship to medical knowledge'. Advances in Health Sciences Education, 17 (3), 311-323 https://doi.org/10.1007/s10459-011-9305-4

Rose, B.W., Kasch, M.C., Aaron, D.H., and Stegink-Jansen, C.W. (2011) 'Does hand therapy literature incorporate the holistic view of health and function promoted by the World Health Organization?' Journal of Hand Therapy, 24 (2), 84-88 https://doi.org/10.1016/i.jht.2010.12.003

Smart, A. (2006) 'A multi-dimensional model of clinical utility'. International Journal for Quality in Health Care, 18 (5), 377-382 https://doi.org/10.1093/intghc/mzl034

Thomas, D.R. (2006) 'A general inductive approach for analyzing qualitative evaluation data'. American Journal of Evaluation, 27 (2), 237-246 https://doi.org/10.1177/1098214005283748

Weinstein, E.C. (2013) 'Three views of artful practice in psychosocial occupational therapy'. Occupational Therapy in Mental Health, 29 (4), 299-360 https://doi.org/10.1080/0164212X.2013.848395

Wong, S.R. and Fisher, G. (2015) 'Comparing and using occupation-focused models'. Occupational Therapy in Health Care, 29 (3), 297-315 https://doi.org/10.3109/07380577.2015.1010130 